\title{
Pharmacotherapy in Childhood Obesity
}

\author{
Peter Kühnen $^{\text {a }}$ Heike Biebermann $^{\text {a }}$ Susanna Wiegand ${ }^{b}$ \\ anstitute for Experimental Pediatric Endocrinology, Charité - Universitätsmedizin Berlin, Corporate Member of \\ Freie Universität Berlin, Humboldt-Universität zu Berlin, Berlin Institute of Health, Berlin, Germany; ${ }^{b}$ Center for \\ Social-Pediatric Care/Pediatric Endocrinology and Diabetology, Charité - Universitätsmedizin Berlin, Corporate \\ Member of Freie Universität Berlin, Humboldt-Universität zu Berlin, Berlin Institute of Health, Berlin, Germany
}

\section{Keywords}

Pharmacological treatment · Obesity · Monogenic obesity · MC4R

\begin{abstract}
Background: The increasing number of obese children and adolescence is a major problem in health-care systems. Currently, the gold standard for the treatment of these patients with obesity is a multicomponent lifestyle intervention. Unfortunately, this strategy is not leading to a substantial and long-lasting weight loss in the majority of patients. This is the reason why there is an urgent need to establish new treatment strategies for children and adolescents with obesity to reduce the risk for the development of any comorbidities like cardiovascular diseases or diabetes mellitus type 2. Summary: In this review, we outline available pharmacological therapeutic options for children and compare the available study data with the outcome of conservative treatment approaches. Key Messages: We discussed, in detail, how knowledge about underlying molecular mechanisms might support the identification of effective antiobesity drugs in the future and in which way this might modulate current treatment strategies to support children and adolescence with obesity to lose body weight.

(c) 2021 S. Karger AG, Basel
\end{abstract}

\section{Introduction}

The increasing number of patients with obesity worldwide is a major challenge for health care systems in industrial and in low- and middle-income countries. It has been estimated that worldwide approximately $13 \%$ of adults (WHO 2018) and 9.3\% of European children suffer from obesity [1]. Rapid weight gain in early childhood results in high risk for obesity in adolescence [2]. The latter is even more dramatic because about $80 \%$ of adolescents with obesity will remain affected from obesity as adults. This underlines the importance of obesity as a lifelong chronic, progressive disease [3]. Furthermore, obesity is accompanied by an increased individual risk for the development of diabetes mellitus type 2 and cardiovascular diseases $[4,5]$, as well as by a decrease in health-related quality of life [6]. It has been estimated that OECD countries will spend $8.4 \%$ of total health expenses each year for the treatment of overweight/obesity and related diseases [1]. For this reason, to "halt the rise of diabetes and obesity" has been included as a target in the global

Peter Kühnen, Heike Biebermann, and Susanna Wiegand contributed equally.

karger@karger.com

www.karger.com/hrp

Karger ${ }^{\prime \prime}=$
Correspondence to:

Peter Kühnen, peter.kuehnen@charite.de 
WHO agenda on prevention and control of noncommunicable diseases $[7,8]$.

Until now, no country in the world has been able to reduce the number of individuals with obesity, which clearly points toward the necessity to establish new treatment strategies. The gold standard for the treatment of overweight/obesity remains a multimodal conservative treatment regime including different experts (physicians, nutritionists, and psychologists) to improve physical activity and reduce caloric intake. Unfortunately, the impact on body weight is overall modest and the majority of patients regain weight within 5 years $[9,10]$.

In the last decade, bariatric surgery has become another therapeutic option for adults and adolescents with obesity. Gastric bypass operation is leading to a reduction of approximately $-26 \%$ of body weight in operated adolescents and approximately $-29 \%$ in adults [11]. However, weight loss response differs dramatically between individuals, and for this reason, a comprehensive stratification of patients who might benefit from surgery is of importance.

Hence, there are major limitations of currently performed conservative and surgical treatment strategies. Against the background of the still remaining medical need to reduce the number of patients with obesity, this review will discuss pharmacological treatment options and its potential value for future approaches with a specific focus on the use of available molecular knowledge to develop pathway-specific drugs with reduced side effects.

\section{Current Status: FDA/EMA-Approved Antiobesity Drugs}

There are only a few FDA/EMA-approved antiobesity drugs available at the moment for the treatment of adult patients and each one with its own limitations. Recently, several reviews provide comprehensive overviews about available antiobesity drugs [12, 13]; hence, we delineate a brief summary about currently approved medications for adult patients:

Orlistat $\left(\mathrm{Xenical}^{\circledR} ; \mathrm{Alli}^{\circledR}\right)$ has been approved by FDA (year: 1999) and EMA (1998). It inhibits a lipase function in the mucous membranes of the intestinal endothelium. Thereby, hydrolysis of triglycerides and fatty acids absorption is reduced. After 1 year, orlistat treatment led to a reduction of $-10.6 \mathrm{~kg}$ (placebo control group: $-6.2 \mathrm{~kg}$ ) and, after 4 years, to a reduction of $-5.8 \mathrm{~kg}$ (placebo control group: $-3.0 \mathrm{~kg}$ ) (XENDOS study) [14]. In total, this is a placebo-subtracted weight loss of $-3 \mathrm{~kg}$ within 208 weeks [12]. Based on the mechanism, steatorrhea, flatus, constipation, fecal incontinence, and occasionally deficit of fat-soluble vitamins are main side effects, observed during orlistat treatment. Because these side effects could potentially have a disturbing influence on daily life, orlistat is uncommon in usual care.

Phentermine/Topiramate $\left(\right.$ Qsymia $\left.^{\circledR}\right)$ has been approved in 2012 by FDA and has not been approved by EMA. This is a combination of norepinephrine activation, GABA agonist and glutamate antagonist, which is leading to a reduction of hunger feeling - although the exact mechanism for this effect remains elusive. In clinical trials, treatment led to a reduction of body weight for $-10.9 \%$ after 1 year (placebo group: $-1.6 \%$ ) (EQUIP) and $-7.8 \%$ (dosage: $7.5 / 46 \mathrm{mg}$ ) and $-9.8 \%$ (dosage: $15 / 92 \mathrm{mg}$ ) after 1 year (placebo group: $-1.2 \%$ ) (CONQUER). In the 2-year extension trial (SEQUEL), a decrease of body weight persists $(-9.3 \%$ [dosage: $7.5 / 46 \mathrm{mg}$ ] and $-10.5 \%$ [dosage: $15 / 92 \mathrm{mg}$ ]) [15, 16]. Side effects consist of hypokalemia, metabolic acidosis, nephrolithiasis, myopia, glaucoma, anhidrosis, paresthesia, dry mouth, anxiety, depression, and increased heart rate [13]. These side effects limit the prescription especially in older people with obesity.

Naltrexone/Bupropion (Contrave ${ }^{\circledR}$; Mysimba $^{\circledR}$ ) has been approved in 2014 by FDA and 2015 by EMA. This is a combination of an opioid antagonist (especially $\mu$-opioid receptor) and an inhibitor of dopamine and norepinephrine reuptake. It has been postulated that the reduction of hunger feeling is mediated via an activation of POMCexpressing hypothalamic neurons $[17,18]$. In the clinical trial, Naltrexone/Bupropion led to a placebo-subtracted weight loss of $-4.7 \mathrm{~kg}$ after 56 weeks (COR-I) [19], -4.9 $\mathrm{kg}$ after 56 weeks (COR-II) [20], $-4.1 \mathrm{~kg}$ after 56 weeks (COR-BMOD) [21], -3.4 kg after 56 weeks (COR-Diabetes) [22], and $-2.7 \mathrm{~kg}$ after 121 weeks (LIGHT) [12]. The side effect spectrum includes nausea, seizures, insomnia, constipation, vomiting, dry mouth, and headache.

Liraglutide (Victoza ${ }^{\circledR}$, Saxenda ${ }^{\circledR}$ ) is a GLP-1R (glucagon-like peptide 1 receptor) agonist and has been approved as an antiobesity drug in 2014 by FDA and in 2015 by EMA. It acts centrally by activating hypothalamic, limbic, and cortical centers of body weight regulation [23, 24]. Moreover, in the periphery GLP-1R activation is leading to inhibition of glucagon and stimulation of insulin secretion and delayed gastric emptying [25]. Within randomized clinical trials (RCTs), liraglutide led to a placebo-subtracted weight loss of $-4.9 \mathrm{~kg}$ after 32 weeks (SCALE-Sleep Apnea study), $-4 \mathrm{~kg}$ after 56 weeks (SCALE-Diabetes study), $-5.6 \mathrm{~kg}$ after 56 weeks (SCALE- 
Obesity and prediabetes study [26]), $-5.9 \mathrm{~kg}$ after 56 weeks (SCALE Maintenance study), and $-4.6 \mathrm{~kg}$ after 160 weeks (SCALE Obesity and Prediabetes 2-year extension study) [12, 27-29]. Major side effects include gastrointestinal symptoms such as nausea, vomiting, and diarrhea.

Semaglutide is another GLP-1R agonist with different pharmacokinetics allowing once-weekly injection. A clinical trial program, including 4 studies, showed $-10.6 \%$ mean change in body weight with semaglutide $2.4 \mathrm{mg}$ and $-7 \%$ with semaglutide $1.0 \mathrm{mg}[124,125]$. Transient and mild-to-moderate gastrointestinal symptoms (e.g., nausea and diarrhea) were the most frequently observed side effects. Semaglutide (injectable once-weekly) was approved by the FDA for obesity in adults in June 2021. Semaglutide in an oral formulation was tested only in type 2 diabetes so far.

In summary, a wide spectrum of pharmacological substances were studied with regard to their impacts on weight course in humans with obesity. Moderate success in long-term weight reduction on one hand and relevant side effects on the other hand limited the frequent use of antiobesity drugs up to date.

\section{Use of Antiobesity Drugs in Children and Adolescents: The Past and the Future}

The situation for children and adolescents differs with regard to available treatment options. For some children and adolescents with obesity, multicomponent lifestyle intervention can be effective. However, for the majority, long-term weight loss and maintenance are not possible to reach, even if pediatric obesity experts fulfill the most versatile challenges by exploiting their expertise in different age-groups.

As for preschool children, aged 0-6 years with overweight or obesity, multicomponent lifestyle interventions appear to be an effective treatment option, but the current Cochrane review is only based on 7 RCTs with a total of 923 participants. A reduction in body mass index (BMI) $z$ score was significantly higher in the intervention groups than the standard care (6-12 months' follow-up: mean difference (MD) -0.3 units (95\% confidence interval [CI] -0.4 to -0.2$) ; p<0.00001) ; 12-18$ months: $\mathrm{MD}-0.4$ units (95\% CI -0.6 to -0.2$) ; p=0.0001$ ). In this age-group, the role of dietary interventions is more equivocal [30].

The intervention review for school children with overweight or obesity, aged 6-11 years, included 70 RCTs with a total of 8,461 participants. Behavior-changing interventions (with various components) compared to standard care significantly reduced BMI and BMI $z$ score. MD in BMI was $-0.53 \mathrm{~kg} / \mathrm{m}^{2}$ (95\% CI -0.82 to -0.24 ); $p<0.00001 ; 24$ trials; 2,785 participants. MD in BMI $z$ score was -0.06 units $(95 \% \mathrm{CI}-0.10$ to -0.02$) ; p=0.001$; 37 trials; 4,019 participants. In general, the evidence quality was low; for example, because only few trials reported adverse event, health-related quality of life or behavior change outcomes [31].

Interestingly, parent-only interventions for childhood overweight or obesity in children aged 5-11 years (intervention review: 20 RCTs, including 3,057 participants) are an effective treatment tool compared to waiting list controls and had similar effects compared to parent-child interventions [32]. This indicates that there is a need to include the situation in the family of children with obesity into consideration before the start of interventions.

A particular challenge is the successful treatment of adolescents with obesity or even extreme obesity. The effect of diet, physical activity, and behavioral interventions for treatment in adolescents aged $12-17$ years was summarized in an intervention review including 44 completed RCTs (4,781 participants) and 50 ongoing studies. In general, behavior-changing interventions were able to significantly reduce BMI, BMI $z$ score, and body weight to a limited extent (BMI $-1.18 \mathrm{~kg} / \mathrm{m}^{2}$ (95\% CI -1.67 to -0.69); 2,774 participants; 28 trials; low-quality evidence; BMI $z$ score -0.13 units (95\% CI -0.21 to -0.05 ); 2,399 participants; 20 trials; low-quality evidence; body weight $-3.67 \mathrm{~kg}$ (95\% CI -5.21 to -2.13 ); 1,993 participants; 20 trials; moderate-quality evidence) [31].

Multidisciplinary lifestyle interventions including a combination of diet, physical activity, and behavioral components slightly reduce childhood and adolescents' obesity and moderately improve health-related quality of life, particularly in comparison to no treatment. The effect is relatively low in age-groups with a high prevalence of overweight and obesity - mainly school children and adolescents [33]. Nevertheless, lifestyle modification therapy is the cornerstone of obesity treatment during childhood and adolescence. Despite the overall low success rate of weight reduction and maintenance, lifestyle intervention is effective in improving obesity-related comorbidities (e.g., insulin resistance, hypertension, hyperlipidemia, fatty liver disease, and exercise capacity), even in the absence of sustained weight loss [34-36]. The limitations of multicomponent behavioral modification programs are grounded in the biological mechanisms of energy homeostasis. The leptin-melanocortin pathway and the incretin system are deeply involved in a complex regulation including peripheral signals, for example, from 
adipose tissue, muscle or gastrointestinal tract, and central signals, for example, from the hypothalamus [37, 38]. There is evidence that this system assists a positive energy balance [39]. In addition to lifestyle modification, antiobesity drugs (and bariatric metabolic surgery) have the potential to discourage these mechanisms. Several medications have been investigated for the treatment of obesity in adults over the last decades [40]. However, total weight loss in 12 months for the 3 monotherapies (orlistat, lorcaserin, and liraglutide) ranged from -5.8 to -8.8 $\mathrm{kg}$ (5.8-8.8\% of initial body weight). Placebo-subtracted weight loss, determined from a meta-analysis, ranged from -2.6 to $-5.3 \mathrm{~kg}$ [41].

In the following section, we will summarize FDA- and EMA-approved and commonly prescribed antiobesity medications in the pediatric population (for efficacy and side effects in adults, see above):

Orlistat $\left(\mathrm{Xenical}^{\circledR}\right)$ is the only FDA (not EMA)-approved drug for the long-term treatment of adolescents with obesity older than 12 years. A large RCT $(N=352)$ analyzed orlistat versus placebo in combination with a multimodal lifestyle intervention, showing a significant weight loss after 12 months' treatment $(-2.61 \mathrm{~kg}$ placebosubtracted weight loss; $p<0.001)$. This trial was also included into a recent pediatric meta-analysis ( $N=779$; average BMI $37.4 \mathrm{~kg} / \mathrm{m}^{2}$ ). There were only small BMI differences between orlistat and placebo [42]. The side effects are comparable to those in adults. Long-term use might potentially cause vitamin and mineral deficiency with a negative impact on growth or pubertal development. However, none of these effects were reported, perhaps due to reduced use of orlistat in adolescents with obesity.

The sympathomimetic amine Phentermine (Adipex ${ }^{\circledR}$, Suprenza ${ }^{\circledR}$ ) was FDA approved already in 1959. There have been very few studies in the 1960s examining phentermine for obesity treatment in the pediatric population with marginal reports about safety and efficacy reported. Since the substance is an amphetamine analog, it acts to increase catecholamines and serotonin in the central nervous system, resulting in appetite suppression. Common side effects may include increased heart rate and blood pressure. Phentermine is FDA (not EMA) approved for short-term treatment $(<12$ weeks) in adolescents $(>16$ years) with obesity because of a lack of long-term observations and frequent side effects. Recent retrospective data in a small adolescent cohort $(N=25)$ suggested a modest effect on BMI \% at 1 month $(-1.6 \%$; $95 \%$ CI: -2.6 , $-0.6 \%$; $p=0.001), 3$ months $(-2.9 \%$; $95 \%$ CI: $-4.5,-1.4 \%$; $p<0.001)$, and 6 months $(-4.1 \%$; $95 \%$ CI: $-7.1,-1.0 \%$; $p=0.009)$ compared with standard care [43].
The combination Phentermine/Topiramate $\left(\right.$ Qysmia $\left.^{\circledR}\right)$ is FDA approved for long-term treatment of obesity in adults (see above). In December 2020, the FDA approved liraglutide $3 \mathrm{mg}$ (Saxenda ${ }^{\circledR}$ ) for the treatment of obesity in adolescents aged 12-17 years with a body weight of at least $60 \mathrm{~kg}$ and an initial BMI corresponding to $30 \mathrm{~kg} / \mathrm{m}^{2}$ or greater for adults (https://www.fda.gov/drugs/drug-safetyand-availability/fda-approves-weight-management-drugpatients-aged-12-and-older). In June 2021, the Committee for Medicinal Products for Human Use (CHMP) from the European Medicines Agency (EMA) decided that the indication for liraglutide $3 \mathrm{mg}$ (Saxenda ${ }^{\circledR}$ ) is expanded for the treatment of obesity in adolescents aged 12-17 years (https://www.ema.europa.eu/en/documents/product-information/saxenda-epar-product-information_en.pdf). Liraglutide $3.0 \mathrm{mg}$ (Saxenda ${ }^{\circledR}$ ) is a once-daily GLP-1 analog with $97 \%$ similarity to natural human GLP-1, a hormone that is secreted in response to food intake.

Like human GLP-1, liraglutide works on glucose metabolism and body weight due to various mechanisms: (i) promoting insulin secretion from pancreatic $\beta$-cells; (ii) reducing glucagon secretion from pancreatic $\alpha$-cells (resulting in hepatic gluconeogenesis); (iii) improving insulin sensitivity; (iv) reducing gastric emptying; and (v) improving central appetite regulation.

Common side effects include nausea, dizziness, abdominal pain, low blood sugar, and pain at the injection site. Other serious side effects may include medullary thyroid cancer (MTC), angioedema, pancreatitis, gallbladder disease, and kidney problems.

Liraglutide causes dose-dependent and treatment duration-dependent thyroid C-cell tumors, at exposures 8 times greater than those used in humans, in both genders of rodent models. Even if the relevance for humans of such tumors identified in rodents has not been determined, liraglutide is contraindicated in patients with a personal or family history of MTC and in patients with multiple endocrine neoplasia syndrome type 2 (MEN 2; https://www. drugs.com/monograph/liraglutide.html). A small, shortterm pediatric RCT studied the safety, tolerability, and pharmacokinetics of liraglutide in adolescents with obesity ( 5 weeks; $N=25 ; 12-17$ years). Twelve hypoglycemic episodes occurred in 8 participants in the liraglutide group and 2 in the placebo group (no severe hypoglycemic episodes). The adult dosing regimen for weight reduction seemed to be appropriate for the use in adolescents as well [44]. Furthermore, the therapeutic effect of high-dose liraglutide ( $3.0 \mathrm{mg} /$ days; Saxenda ${ }^{\circledR}$ ) additional to lifestyle intervention on BMI in adolescents with obesity was addressed in a larger RCT $(N=251 ; 12-17$ years; a 56 -week 
treatment period; a 26-week follow-up period). A liraglutide decrease in BMI-SDS in the liraglutide group was superior to placebo after 56 weeks (estimated difference, -0.22 ; $95 \%$ CI: -0.37 to $-0.08 ; p=0.002$ ). BMI reduction of at least $5 \%$ was achieved more frequent with liraglutide than with placebo ( $43.3 \%$ vs. $18.7 \%)$. BMI-SDS regain in the follow-up period was higher in the liraglutide group (estimated difference, 0.15; 95\% CI, 0.07-0.23). At 56 weeks, cardiometabolic parameters and weight-related quality of life did not differ between both groups [45]. Results and conclusions of this study were discussed intensively. Frequent gastrointestinal side effects could potentially induce weight reduction and could be associated with malabsorption [46]. Weight regain immediately after the end of medication as well as the potential risk of severe long-term adverse events as MTC requires a critical discussion of benefits and risks for the use of liraglutide in adolescents with obesity [47]. Even with some promising evidence for the efficacy and safety of liraglutide in treatment of adolescents with obesity, liraglutide should only be used as an adjunct to intensive lifestyle intervention [48].

In children and adolescents with type 2 diabetes and obesity, liraglutide $(1.8 \mathrm{mg} /$ day; additional to metformin and/or insulin) improved glycemic control in relation to placebo [126]. In a further pediatric RCT with exenatide (Byetta ${ }^{\circledR} ; N=44$ ), a substance related to liraglutide and with similar effects on the GLP-1R, a 6-month weekly injection leads to the modest BMI-SDS reduction and a moderate improvement of glucose tolerance and serum-cholesterol in adolescents with obesity [49]. Exenatide (Byetta ${ }^{\circledR}$ ) is FDA/EMA approved for type 2 diabetes mellitus in adults, but not for obesity or younger age-groups. Some other medications, primarily not FDA/EME approved for obesity in childhood, have been applied in clinical studies, recording also body weight as the second end point.

Metformin (an activator of the protein kinase pathway) is the first-line medication for type 2 diabetes mellitus in patients older than 10 years. In addition, for the polycystic ovary syndrome in females, especially in combination with obesity and insulin resistance, metformin is indicated. There are some reports about metformin modestly reducing body weight in adolescents with obesity, even with improving insulin sensitivity - but the evidence remained elusive [50-52]. Frequent gastrointestinal side effects like diarrhea or flatulence possibly cause reduced food intake. Lactic acidosis is a very rare but severe side effect mainly in older patients with renal insufficiency.

Topiramate (Topamax ${ }^{\circledR}$, central acting via modulation of neurotransmitters) is indicated for the treatment of epilepsy for children older than 2 years and for migraine or cluster headache in adolescents older than 12 years. The combination with phentermine is approved for long-term treatment of obesity in adults (see above), but also in adult patients with binge-eating disorder and bulimia nervosa [53]. There is some evidence that topiramate could support weight reduction in addition to lifestyle intervention in adolescents with obesity [54], based on a small observational study $(N=28$; mean age $15.2 \pm 2.5$ years, mean baseline BMI $46.2 \pm 10.3 \mathrm{~kg} / \mathrm{m}^{2} ; 6$-month change in BMI -4.9, $95 \%$ CI -7.1 to $-2.8, p<0.001$ ) [55]. Severe potential side effects, such as kidney stones, metabolic acidosis, cognitive dysfunction, and teratogenicity (mandatory contraception for females), is limiting even the off-label use.

Central nervous stimulants are approved for children with attention-deficit hyperactivity disorder. A common side effect is decreased weight due to decreased appetite or diarrhea, with a long-term effect on growth and pubertal development. A negative impact on brain maturation was demonstrated in animal models [56, 57]. Hypothalamic obesity (following CNS insult, e.g., craniopharyngioma, meningitis) in children and adolescents is a challenge for patients, families, and treatment teams because alteration of the hypothalamus results in the combination of decreasing physical activity (lethargy) and increased hunger feeling. Central nervous stimulants were at least able to prevent further weight gain in small case studies up to 1 year of follow-up $[58,59]$. The clinical experience provides evidence that the effect in children and adolescents with common obesity is often the very reverse: low food intake during school hours, followed by food craving in the afternoon and eating during the night (in combination with media consumption). It is therefore essential to critically evaluate the off-label use of central nervous stimulants on an individual level and to use central documentation of patient data (pseudonymized) to gain new insights.

In summary, the diversity of primary diseases in children and adolescents with obesity (common obesity, monogenic obesity, and syndromic obesity) results in a greater variety of pharmacological options [60]. But the effect is comparable with the results in adults with obesity. Additional lifestyle intervention is considered to be the fundament for all age-groups.

\section{Proof of Concept: Pharmacological Treatment of Patients with Monogenic and Syndromic Obesity}

In contrast to patients with common obesity, pharmacological treatment strategies for patients with monogenic or syndromic obesity differ substantially in some cases. 
The knowledge about the molecular cause for the development of obesity in these particular patients led to the possibility to a mechanism-driven treatment approach.

Patients with Prader-Willi syndrome (or other obesity syndromes) suffer from hypothalamic obesity. The situation is even more difficult because of existing mental handicaps and reduced muscle mass. While feeding problems in floppy infants are the prominent clinical features early in life, food graving and hypothalamic obesity usually start at kindergarten age. Over the years, many substances were used in single or small case studies to prevent or treat this condition, but without enjoying any great success; for example, clinical studies on oxytocin (or oxytocin analogs) have resulted in conflicting outcomes about hyperphagia and repetitive behaviors in young children with PWS.

More recently, a methionine aminopeptidase 2 (MetAP2) inhibitor (Belorani), originally aproved as an angiogenesis inhibitor for the treatment of cancer and supposed to directly act on the adipose tissue, showed promising results in phase III study, with significant weight reduction and improved hyperphagia-related behavior in patients with PWS. Further development was stopped because of a severe side effect (2 deaths) [61]. Exenatide $\left(\right.$ Byetta $\left.{ }^{\circledR}\right)$ reduced significantly appetite scores and $\mathrm{HbA} 1 \mathrm{c}$ in 10 adolescents and young adults with PWS (13-25 years), but without effect on BMI [62].

Rimonabant (endocannabinoid receptor $\mathrm{CB} 1$ antagonist) was a promising candidate and tested $2006-2008$ as antiobesity medication in patients with PWS. Because of psychotic reactions and depression, $50 \%$ of subjects on treatment withdrew and the study was terminated [63]. These examples illustrate the difficulties to treat hypothalamic obesity in patients with PWS successfully [64, 65].

The discovery of the leptin-melanocortin signaling cascade was a milestone for the understanding of central body weight regulation. The analysis of rodent models with defects in leptin or leptin receptor gene (ob/ob mice $[66]$ or $d b / d b$ mice $[67,68])$ provides new insights into the hormonal regulation of satiety. Leptin activation of leptin receptors within the hypothalamus leads to the secretion of melanocyte-stimulating hormones ( $\alpha$ - and $\beta-\mathrm{MSH}$ in humans) derived from POMC (proopiomelanocortin)-expressing neurons. MSH derivatives are ligands for the G-protein-coupled receptor (GPCR) MC4R (melanocortin 4 receptor) in the paraventricular nucleus. Gene mutations in one of the involved genes lead to impaired pathway function and severe hyperphagia and obesity in animal models and hu- man variant carriers [69-74]. Hope and enthusiasm raised after successful leptin treatment of leptin deficient rodents and first leptin treatment of severely obese LEP gene mutation carriers $[75,76]$. Here, leptin led to a substitution of the missing signal in these patients and restored function of the leptin-melanocortin signaling pathway. This led to normalization of the initially increased hunger feeling and reduction of body weight. Unfortunately, leptin treatment is not successful in patients with nongenetic obesity to decrease body weight [77]. Apart from leptin, studies had been performed to investigate the treatment with MC4R agonists. Former first-generation MC4R agonist led to a reduction of food intake in POMC-deficient rodents, but studies in humans were accompanied by the occurrence of severe side effects like increased blood pressure or were not successful to induce weight loss [78, 79] (see Drug Failure and Its Molecular Mechanisms: Scope for Improvement). However, recently, a new MC4R agonist setmelanotide (former name: RM-493, BIM-22493) has been studied initially in an investigator-initiated phase 2 proof-ofconcept study (EudraCT No. 2014-002392-28) in patients with mutations in the genes POMC or LEPR. In 2 enrolled POMC deficient patients, this treatment led to a reduction of body weight for $-51.0 \mathrm{~kg}$ after 42 weeks and $-20.5 \mathrm{~kg}$ after 12 weeks of treatment. Furthermore, patients with $L E P R$ mutation $(n=3)$ lost $-25.1 \mathrm{~kg}$ (after 61 weeks), $-13.9 \mathrm{~kg}$ (after 36 weeks), and $-10 \mathrm{~kg}$ (after 13 weeks). These results were confirmed in phase 3 trials (ClinicalTrials.gov, NCT02896192 and NCT03287960) in which patients with POMC deficiency lost $-25.6 \%$ and LEPR-deficient patients lost $-12.5 \%$ of pretreatment body weight. Importantly, no cardiovascular adverse events have been detected. However, skin hyperpigmentation due to cross-activation of the melanocortin 1 receptor (MC1R) has been observed in the majority of treated patients. Setmelanotide has been approved for patients with POMC/PCSK1 and LEPR deficiency by the US Food and Drug Administration (FDA) in 2020. Of note, prior to the usage of setmelanotide as an treatment option, loss of function of identified mutations in candidate genes of the leptin-melanocortin pathway has to be tested in the state-of-the-art functional characterization. Ongoing studies investigate whether further groups of patients might benefit from the MC4R agonist treatment. Within a phase 2 study including patients with the ciliopathy Bardet-Biedl syndrome/Alström syndrome, setmelanotide led to a mean reduction of $-16.3 \%$ of pretreatment body weight after 12 months of treatment $(n=$ 7) $[80]$. 
Apart from leptin and MC4R agonists, recently the GLP-1R agonist liraglutide has been tested in patients with heterozygous and homozygous MC4R mutations $[81,82]$. Over a maximum period of 16 weeks, liraglutide led to a reduction of $-9.7 \mathrm{~kg}$ in the homozygous MC4R variant carrier and to a reduction of $-6.8 \mathrm{~kg} \pm 1.8 \mathrm{~kg}$ in heterozygous $M C 4 R$ variant carriers. In 28 matched control participants, the treatment led to a decrease of body weight for $-6.1 \mathrm{~kg} \pm 1.2 \mathrm{~kg}$ after 16 weeks.

These examples indicate that there is growing evidence that there are now new pharmacological treatment options available, which might be beneficial for patients with certain monogenic obesity types. This is important because conservative treatment strategies (increased exercise and reduced caloric intake) and even in some cases with biallelic gene mutations bariatric surgery do not lead to a long-lasting reduction of body weight. However, in the majority of children and adolescents with obesity, a precise gene mutation is not explaining the development of obesity. It might be of interest whether heterozygous variant carriers (e.g., for the genes POMC and $L E P R$ ) would also benefit from such a pharmacological treatment. However, this question remains to be answered.

\section{Drug Failure and Its Molecular Mechanisms: Scope for Improvement}

All of the above-described pharmaceutical US FDA/ EMA-approved treatment options were either only suboptimal effective in a few patients or cause adverse side effects but are not suitable for a generalized treatment of children with common obesity. The result of so far available studies might be that not a "simple and safe" obesity treatment is successful for most children with obesity and that there is a need to rethink the currently available multidisciplinary concept of obesity treatment. It is now time to combine the current concepts with genetic studies and available molecular biology information of those cells/ neuros/tissues that are involved in energy homeostasis to achieve an obesity 2.0 treatment strategy.

Here, our intention is to highlight one of the molecular players that are involved in weight regulation and might serve as a potential treatment target: GPCRs.

\section{General Aspects of Consideration If a GPCR Shall Be}

Used as Drug Target

GPCRs are involved in many if not in all physiological functions [83], which classified them as drug targets. Indeed, currently approximately $35 \%$ of approved drugs in the USA and Europe target a GPCR $[83,84]$. For antiobesity treatment, a variety of such GPCRs were targeted such as the cannabinoid 1 receptor (CB1R), the serotonin $2 \mathrm{C}$ receptor (5HT2CR), the GLP-1R, or the MC4R. Unfortunately, many of former approved drugs were now withdrawn from the market because of severe side effects.

To understand why these side effects occur offers the chance to improve a drug design and to make the treatment more specific and effective. To achieve this, a general understanding about the receptors' function is necessary. Very simplified, GPCRs consist of 7 a-helical transmembrane-spanning domains that are connected by 3 extracellular and 3 intracellular loops with the N-terminal part at the extracellular space and the C-terminus intracellularly [85]. Based on structural aspects, GPCRs were separated in 5 different classes [86]. Class A is by far the largest class. In this class are mainly receptors with short N-terminal domains and a structural homology to adrenergic receptors or rhodopsin. Receptors with longer $\mathrm{N}$-terminal domains belong to class B such as the GLP$1 \mathrm{R}$, which is the target for GLP-1 analogs such as liraglutide.

When an endogenous ligand (a synonym for an agonist or a hormone stimulating signaling) binds to the receptor, it occupied the orthosteric binding site, which is for class A receptors mainly located within the transmembrane bundle. Receptors with a larger extracellular domain such as GLP-1R bind its endogenous ligand at the N-terminal domain. If the therapeutic ligands are designed, they will bind either to the orthosteric binding site and thereby competing with endogenous ligand binding, or they use another binding site also known as allosteric binding site, which differs from the orthosteric binding site.

Binding of a ligand, either the endogenous one or an artificial, results in a conformational change of the receptor, leading to the activation of signaling, which is, for example, $G$ protein activation, and subsequently modifies second messenger concentrations (e.g., cyclic AMP).

However, the situation is much more complex because:

1. The GPCR of interest is activated by several endogenous ligands (e.g., the MC4R by $\alpha-\mathrm{MSH}$ and $\beta-\mathrm{MSH}$ ) [87].

2. In addition to endogenous ligands also an antagonist or an inverse agonist exists (e.g., AGRP at MC4R) (Fig. 1) [87].

3. A ligand can induce more than one signaling pathway (e.g., MC4R: Gs, Gi, Gq/11, ERK, and $\beta$-arrestin) [88, 89] (Fig. 2). 


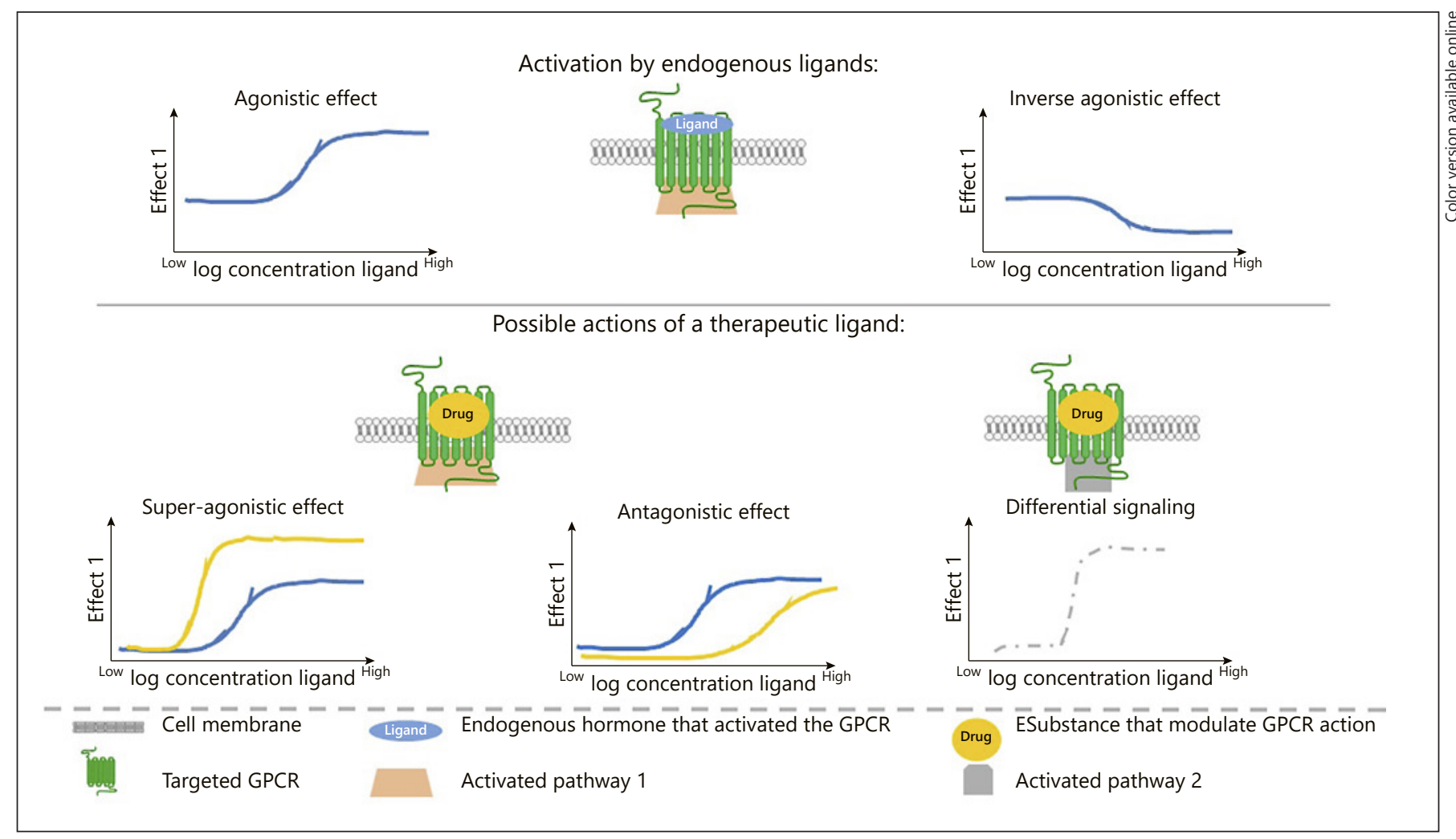

Fig. 1. Schematic illustration of GPCR activation by endogenous ligands and possible therapeutic drug effects at this GPCR. GPCRs are prominent targets for drug development, for example, to treat obesity. The upper part of the cartoon demonstrates 2 possible actions at a GPCR of interest that are exerted by the endogenous ligand (e.g., a hormone). On the left site, the action of the endogenous ligand at its GPCR to activate the major signaling pathways (effect 1) is depicted in a blue concentration-response curve. In case of GPCRs with high constitutive activity (activity in the absence of ligand), the endogenous ligand can act by reducing the constitutive activity of effect 1 , known as an inverse agonistic effect, shown on the upper right site. On the lower part of the cartoon, some possible effects of a therapeutic sub-

4. The GPCR of interest is expressed in different tissues: for example, obesity targets CB1R, 5HT2CR, and MC4R are centrally and peripherally expressed [90].

5. In different tissues, a GPCR may activate different signaling pathways $[89,91]$.

6. The GPCR of interest may function as a homodimer (one GPCR interacts with the same GPCR) or as a heterodimer (GPCR of interest interacts with another GPCR or another membrane protein). These interactions are dependent on the tissue of expression and may change the signaling properties [92] (Fig. 2c, d).

7. Intracellular proteins may interfere with GPCR function [91]. As the expression of these proteins is cell- stance, a drug (e.g., a peptide or a small molecule) at the GPCR, are shown. One action can be hyperstimulation of the GPCR by the drug to induce pathway 1 (effect 1 ) shown on the left side (higher activation by the drug in yellow compared to the endogenous ligand in blue). In the middle, another possibility is indicated where inactivation (in yellow) of the effect 1 of the endogenous ligand (in blue) by an antagonist is shown (shift of the concentration response curve to higher concentrations for activation). On the left side, a very attractive possibility is depicted where a drug can activate an additional pathway (effect 2) in comparison to the endogenous ligand. This so-called biased agonist can exert differential signaling. GPCR, G-protein-coupled receptor.

type specific, they thereby also modify the signaling properties of the GPCR of interest (Fig. 2b).

8. It might matter where in a cell or a neuron a GPCR of interest is located. Compartmentalization might influence the signaling outcome of a targeted GPCR as it is the case for $\beta$-adrenergic receptors in cardiomyocytes. Here the Gs-coupled $\beta 2$ adrenergic receptor (ADRB2) exerts cAMP signals in deep transverse tubules, whereas the ADRB1 is distributed all over the healthy cardiomyocyte. In the disease condition, this "healthy" distribution is destroyed and the ADRB2 is diffusely distributed, which might contribute to the disease phenotype [93]. In contrast to the previously expected 


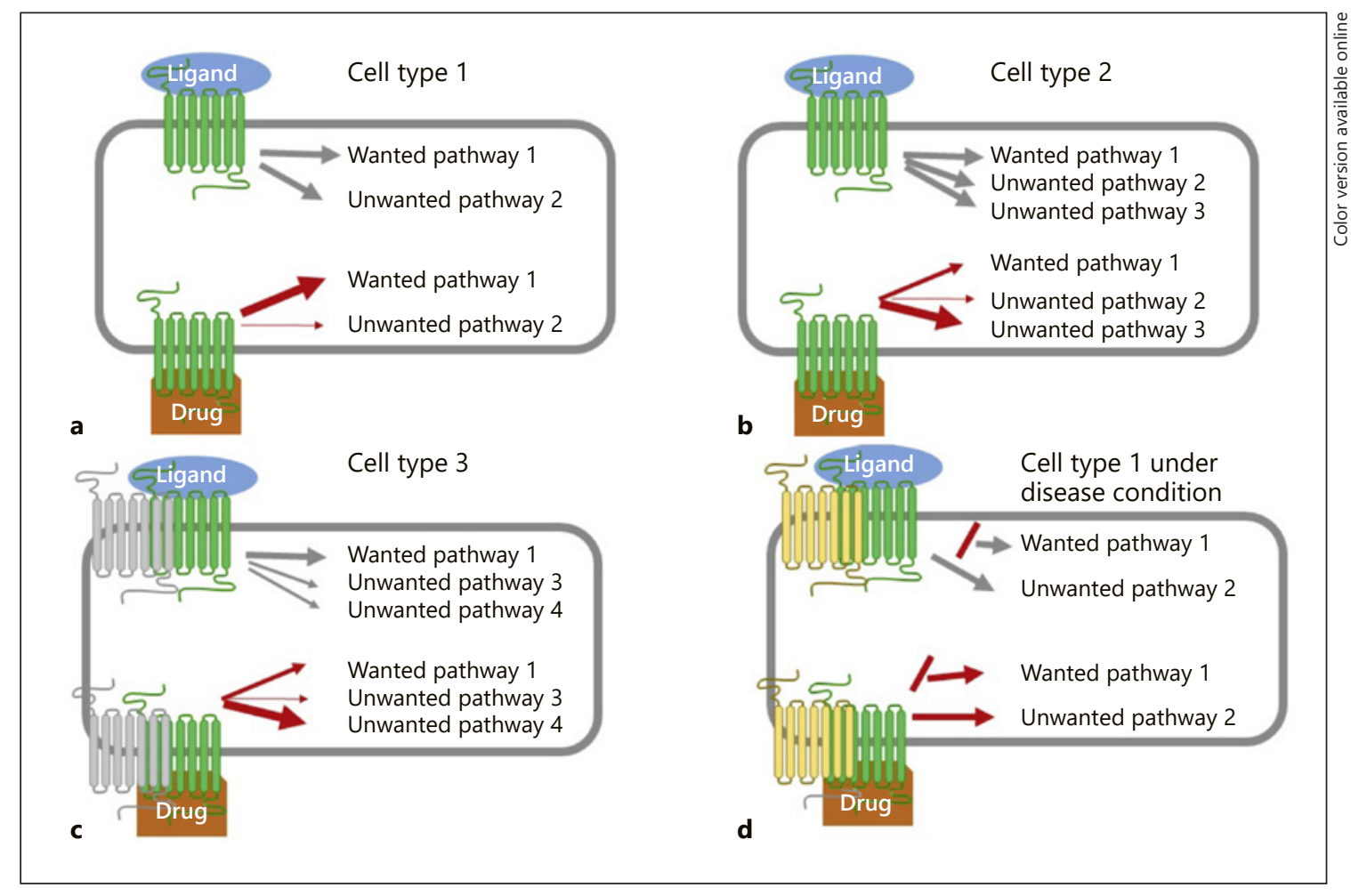

Fig. 2. Schematic illustration of wanted and unwanted effects if a drug target is a GPCR of interest. The GPCR of interest (in green) is activated by its endogenous ligand (in blue). Activated signaling pathways of the ligand are shown in gray, and the strength of the activation corresponds to the thickness of the arrows. The therapeutic ligand (drug in dark orange) activates signaling pathways indicated by red arrows, and the strength of the activation corresponds to their thickness. a Here the optimal situation is illustrated: The pathways of the GPCR of interest that should be targeted are known from signaling studies with the endogenous ligand. A drug is developed, which preferentially activates (red arrows) the pathway, which is of therapeutic interest (wanted pathway 1) but does not or only to a minor extend activate the side effect causing pathway 2. b GPCRs are often expressed in $>1$ type of cells or neurons. Here the case is depicted in which a cell type differs to the one in a activating more pathways, for example, due to other or different intracellular signaling proteins. In this case, in addition to the therapeutic important pathway 1, also pathways 2 and 3 are already activated by the endogenous ligand. If a drug targets the

diffusion of cAMP through the cell, data now demonstrate that the cAMP signal is immobile in the basal state by binding to cAMP binding sites [94].

9. Disease progress of the metabolic status may influence the expression of the GPCR of interest. We have to expect that many GPCRs will be expressed on hypothalamic neurons that should be targeted for treatment. The expression of these GPCRs might be influenced due to hypothalamic inflammation, which is related to receptorof interest in this cell system, it might be that in addition to activation of the wanted pathway 1 (not as much activated compared to cell type 1 in a) unwanted pathways might be activated. c GPCRs often form homo- or heterodimers. Here as an example the heterodimeric state is shown by an additional GPCR (in gray). This constellation can modulate the signaling properties of the GPCR of interest, here shown as the activation of additional pathways after challenge with the endogenous ligand (pathways 3 and 4, both of them are unwanted in a therapeutic intervention). If a drug targets this heterodimer, it might be that in addition to the wanted effect (activation of pathway 1) also the unwanted pathways 3 and 4 are activated. $\mathbf{d}$ Under the disease condition, it might be that the content of interacting proteins of the GPCR of interest might change. This could be GPCRs, which are shown here in yellow, or other membrane proteins. This interaction can theoretically lead to uncoupling of the signaling pathway 1 that is needed for therapeutic intervention. In this case, the drug is ineffective, as due to uncoupling the therapeutic important pathway cannot be activated anymore. GPCR, G-protein-coupled receptor.

obesity. In this case, overexpression of so far non- or low-expressed GPCRs may occur as this is the case in bronchial asthma. Here, standard asthma treatment uses the bronchodilatation effect of activated $\beta$-adrenergic receptors; however in case of a respiratory infection, prostaglandin receptors are highly expressed and these receptors cause an uncoupling of adrenergic receptors from its signaling pathway $[95,96]$ (Fig. 2d). 
Therefore, if a GPCR of interest should be targeted, a careful knowledge about the signaling pathway of the receptor is needed. This is of specific interest if the signaling properties may vary due to the expression of different cell types or the signaling outcome (the biological effect). In case of activation of the MC4R, which is expressed in the hypothalamus where it regulates feeding behavior as well as in the penile tissue, where it is involved in reproduction, overactivation of the receptor (Fig. 1) by artificial ligands might have multiple effects, which are not always wanted at a time [96-99].

To obtain specific knowledge about the receptor of interest is by far not trivial. Most knowledge was obtained by in vitro studies in nonhomologous cell systems. Since many GPCR involved in weight regulation are expressed in the brain [90], data from rodent studies may help in some cases; however, it has to be kept in mind that the expression profile of GPCRs in different areas of the mouse brain may be different to human brain, and differentially expressed GPCR might interact with GPCRs of interest [100]. For this reason, it might sometimes take many years since a complete signaling profile of a GPCR is evaluated [88].

Once the signaling pathway, which should be modulated, is identified, for example, the agonistic profile of the endogenous ligand or the inverse agonistic profile, a drug may enhance or reduce the endogenous ligands' signaling (overactivation or hyperstimulation vs. inactivation by antagonism) (Fig. 1). Over the last few years, it became more and more evident that an elegant way of drug development is so-called biased ligands, which have a signaling profile different to the endogenous ligand. A biased ligand is a ligand that is capable to activate signaling pathways different to the endogenous ligand; for example, if the endogenous ligand activates Gs signaling and $\beta$-arrestin recruitment and $\beta$-arrestin recruitment cause unwanted side effects, a biased ligand can, for example, only activate Gs signaling with no or only minor effect on $\beta$-arrestin recruitment. With these drugs, a specific pathway may be activated and by this activation an unwanted pathway can be reduced or excluded $[89,101,102]$.

In addition, another aspect has to be taken under consideration: the binding mode of the endogenous ligand versus the drug. By definition the endogenous ligand binds to the orthosteric binding pocket. A designed drug that can attract this orthosteric pocket will thereby compete with the endogenous ligand or bind to another binding pocket, allosteric binding, and change by this the conformation of the reception, which may interfere with endogenous ligand binding [103].
Next, the mode of action matters: a drug can be a positive allosteric modulator, which by this alters the affinity or the efficacy of the endogenous ligand, and a negative allosteric modulator, which negatively alters the affinity or the efficacy of the endogenous ligand [104].

If a drug exerts the wanted effect (reduction of body fat) but also causes unwanted effects, the first enthusiasm due to their weight-lowering effects is dampened by recognition of side effects such as psychiatric side effects in case of CB1 antagonists (rimonabant; Acomplia ${ }^{\circledR}$ ) [105]. MC4R agonists were either ineffective in reducing weight, for example, MK-0493 [79] or cause cardiovascular side effects such as LY2112688 [106]. For MC4R, however also a very effective drug exists, setmelanotide, which is highly effective in reducing hyperphagia and food intake in patients with a defect in the leptin-melanocortin pathway, such as POMC- or LEPR-deficient patients [107, 108]. 5-HT2CR ligand lorcaserin (Belviq ${ }^{\circledR}$ ) is highly selective and reduces hunger and food intake; however, due to the induction of tumors and psychiatric side effects, it was withdrawn from the market [13]. In any case, either the targeted GPCR is activated in cells or tissues, where it should not be activated, or the signaling effect of the drug results in unexpected effects because the full spectrum of signaling events of the targeted GPCR is not fully unraveled.

\section{Examples of Targeted GPCRs for Antiobesity \\ Treatment}

We will highlight 3 GPCRs that were targeted as obesity treatment over the last few years. These 3 GPCRs are accepted for a long time as potent obesity treatment targets of therapeutic substances - however, the efficacy and safety might be a matter of concern.

\section{CB1R: The Location Matters}

The CB1R is part of the endocannabinoid systems that is involved in many biological processes including appetite regulation and mood [109]. The CB1R is expressed centrally and in many peripheral tissues. Activation of CB1R stimulates feeding; thus, the design of inverse agonists at CB1R such as SR141716A (rimonabant) should counteract feeding as obesity treatment. Preclinical and clinical studies proved rimonabant as effective in reducing food intake, and it was approved as antiobesity therapeutic. Unfortunately, although rimonabant was effective in reducing weight, it causes severe psychiatric side effects such as depression anxiety and suicide [110], 


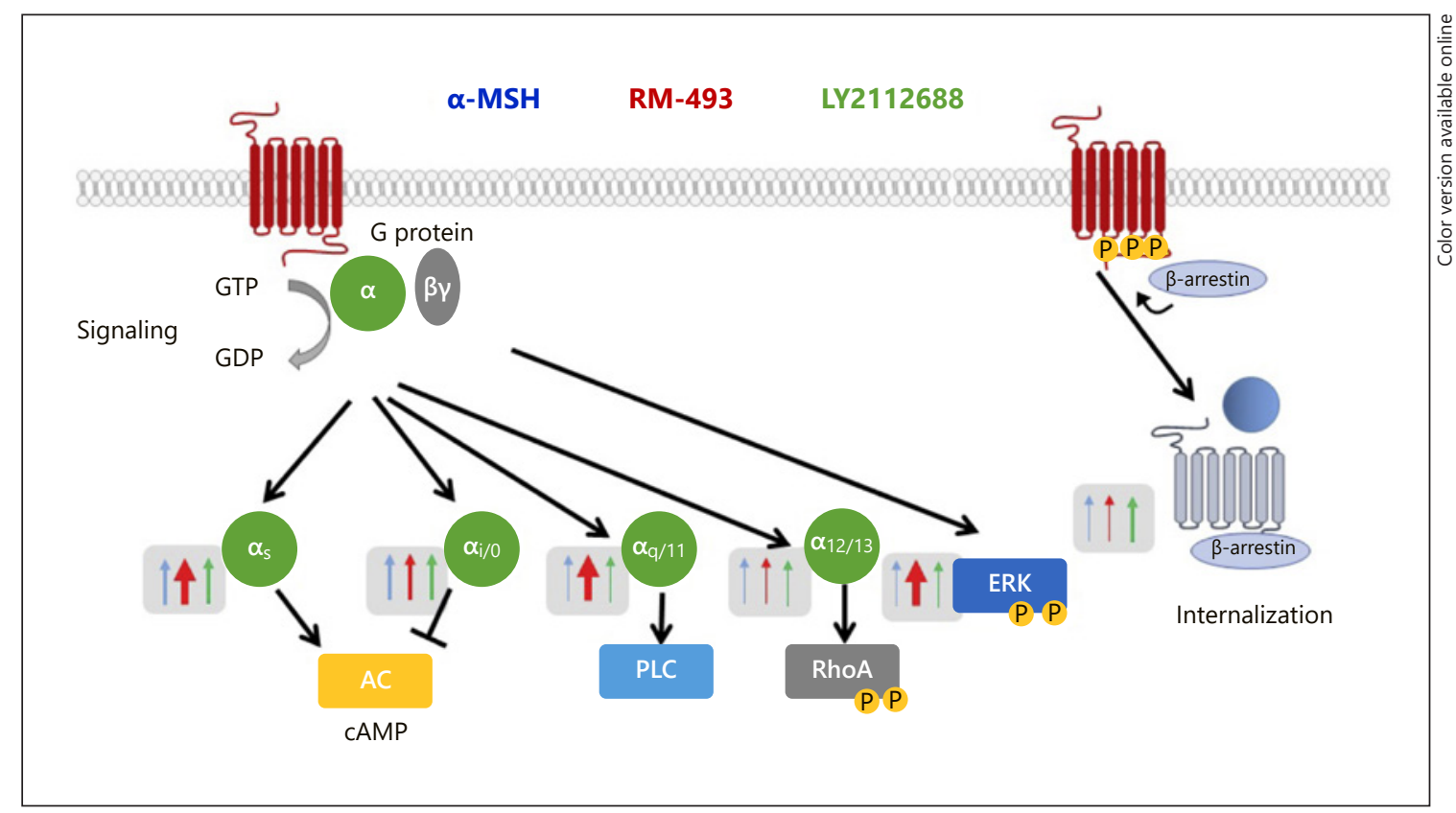

Fig. 3. Illustration of activated signaling pathways and $\beta$-arrestin recruitment after challenge with $\alpha-\mathrm{MSH}$, setmelanotide, and LY2112688 at MC4R. The MC4R can couple to all $4 \mathrm{G}$ protein families, however, with different efficacies. The main signaling pathway is the activation of Gs, shown on the left side. The potency of activation with $a-\mathrm{MSH}$ (in blue), setmelanotide (in red), and LY2112688 (in green) is indicated by different thicknesses of arrows (own unpublished data). The effect of setmelanotide to activate $\mathrm{Gq} / 11$ and ERK signaling is superior to the other ligands and most likely the reason for the hyperphagia reducing effect. Activation of Gi/o and G12/13 and $\beta$-arrestin recruitment are comparable for all ligands. MSH, melanocyte-stimulating hormone. which result in the withdrawn of rimonabant from the market.

Since CB1R is expressed not only in the brain but also in the peripheral tissue such as muscle and adipose tissue, efforts were undertaken to design a CB1R inverse agonist that acts only in the periphery. TM38837 can only target $\mathrm{CB} 1 \mathrm{R}$ in the periphery because the penetrance in the central nervous system is reduced and acts as an inverse agonist comparable to rimonabant. Current studies suggest that the side-effect spectrum of this substance to induce psychiatric side effects was only seen at doses 100 times higher than used with rimonabant. More peripheral acting $\mathrm{CB} 1 \mathrm{R}$ ligands are currently under investigation. A very comprehensive review [105] summarized all currently available CB1R ligands.

\section{MC4R: The Signaling Pathway Matters}

Already in the late 1980s of the last century, it became apparent that melanocortins are capable to reduce food intake [111]. The first melanocortins used were POMC- derived peptides in which the conserved binding motif at melanocortin receptor (HFRW, amino acid single letter code) exists. The design of the first potent melanocortin ligands was tested for their role in pigmentation by activating peripheral MC1R [112]. Since then, linear and cyclic peptidic MC4R ligands as well as small molecules acting specifically at melanocortin receptors were designed $[106,113]$. In clinical studies, these ligands such as MK-0403 did not result in weight reduction, leading to the assumption that the MC4R is not an optimal target for obesity treatment [79], or cause severe side effects such as LY2112688 [106]. Nevertheless, more melanocortin agonists were created and recently one of them, RM-493 (setmelanotide), was highly effective in reducing of hyperphagia and body weight in POMC-deficient patients (see Proof of Concept: Pharmacological Treatment of Patients with Monogenic Obesity). After this first study, to explain why setmelanotide was more effective in weight reduction than other melanocortin receptor ligands, it was speculated that signaling pathway differences in the activation of Gs signaling, which is the primary MC4R pathway, might be involved [114]. Al- 


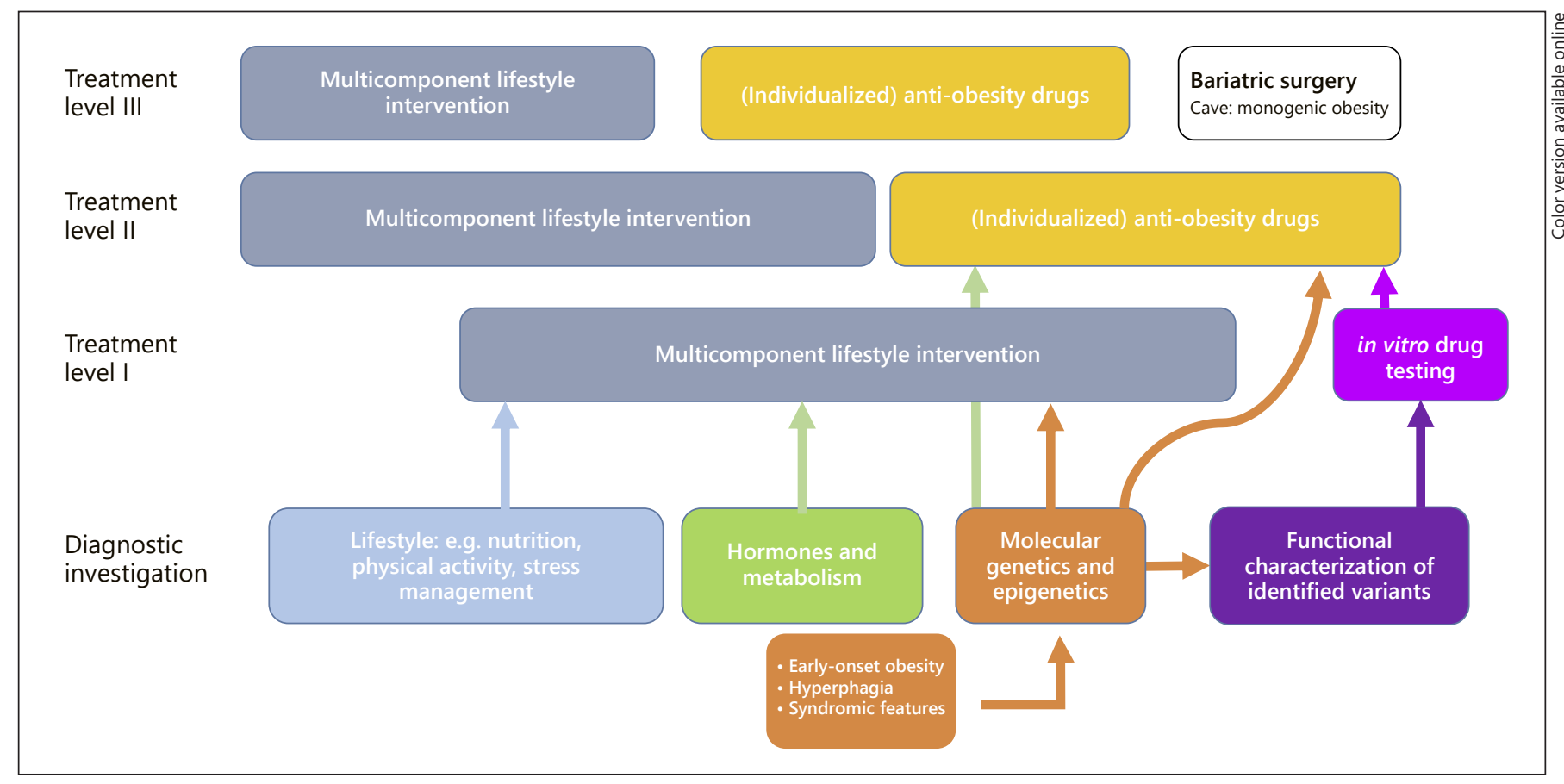

Fig. 4. To improve the treatment of nonadult patients with obesity, there is a need to adapt current strategies. We outline a multilevel diagnostic and treatment approach for children and adolescents with obesity considering the individual aspects of lifestyle, metab- olism, and the genetic background. At the moment, bariatric surgery is only recommended for adolescent patients after completing growth development. ready at this point, it has been speculated that Gq/11 signaling might play a role. This assumption was further strengthen by studies in mice, where either Gs or Gq/11 signaling in the hypothalamic paraventricular nucleus was abolished [115]. In the absence of $\mathrm{Gq} / 11$ signaling (active Gs signaling), activation of the MC4R causes an increase in the systolic blood pressure but not a reduction of food intake, whereas inactivated Gs signaling (active $\mathrm{Gq} / 11$ ) does not influence blood pressure but leads to a reduction of food intake [115]. These data confirm an older study where Gs signaling was disrupted by targeted deletion of CREB. In these mice, food intake was still activated by a potent MC4R ligand [116]. Characterization of the functional role of setmelanotide indeed points to a vital role of non-Gs signaling, which is most like activation of Gq/11 [108]. In-depth characterization of endogenous ligand $\alpha-\mathrm{MSH}$ versus setmelanotide and LY2112688 points to profound differences in the signaling profile of the MC4R ligands, which may be the cause for the different level of efficacy at MC4R to reduce body weight in patients (Fig. 3).

\section{GLP-1R: Peripheral and Central Action}

The GLP-1R is expressed in the periphery mainly on pancreatic $\beta$-cells, in the stomach and gut [117]. In addition, GLP-1R is also expressed in various brain regions [13]. The beneficial role of GLP-1 analogs to reduce blood glucose levels in type 2 diabetic patients is known for a long time [118]. The stimulation of GLP-1R in $\beta$-cell promotes the insulin release. The central effect of insulin together with the anorectic effect of activated brain GLP-1R causes a reduction of body weight. This dual function of GLP-1R analogs such as liraglutide makes them a suitable therapeutic option in patients with common obesity and associated comorbidities [118].

Over the last years, several GLP-1R analogs were designed with the intention to enhance the half-life of GLP1. In addition, single molecules have been created, which target more than one receptor. This includes the GIP receptor (GIPR) to take advantage of desired metabolic effects of glucose-dependent insulinotropic peptide GIP and/or the glucagon receptor to lower body weight [119] (for excellent overview, see Ref. [120]). Recent in-depth characterization of native GLP-1 compared to GLP-1 ag- 
onists with potencies at GLP-1R and GIPR reveals that the superior effect of dual agonists is based on biased signaling compared to native GLP-1 with reduced rates of receptor internalization [121].

These single-molecule multiagonist ligands are a new and very promising class of antiobesity treatment options, which foster the superior effects of anorectic ligands and reduce potential side effects. In addition, a further very elegant concept of introduction of weight-regulating molecules into target cells is the so-called Trojan-Horse concept. Here a GPCR ligand, for example, glucagon or GLP-1, serves as a shuttle to transfer a molecule with weight-reducing capability, for example, triiodothyronine or estrogen $[122,123]$.

\section{Summarizing Remarks and Outlook}

It is clearly evident that a new treatment strategy is necessary to support children and adolescents with obesity to decrease especially the number of patients, in whom comorbidities like diabetes mellitus type 2 or cardiovascular diseases occur. Effective treatment regimens would be a milestone and would affect the health situation worldwide dramatically. The knowledge gathered in the last few years on different levels might allow a more sophisticated and individual approach. However, to achieve this, there is a need for a close cooperation and interaction between basic scientists and clinicians. In addition, it has to be pointed out that the treatment is only one side of the medal. New avenues of treatment will not be a breakthrough, if not in parallel prevention strategies are established.

Therefore, the overall intention is to develop an efficient and safe treatment option for children with obesity. Currently ongoing new achievements however point to a so far underestimated potential of a modular, personalized strategy that orchestrates: (i) an already established procedure such as the interdisciplinary involvement of pediatricians, psychiatrists, ecotrophologists, and many more with (ii) life-style intervention, in addition to (iii) available new basic science achievements ranging from genetic analysis (exome sequencing and single-cell RNA analysis) and pathway analysis.

As a result, a new case-sensitive strategy for each patient has to be designed (Fig. 4), which is able to react with changes in the patient's situations, for example, adaptation of treatment after initial weight loss to avoid weight regain and remain the improvement of glucose tolerance (Fig. 4). It is of importance to underline that the current- ly available antiobesity drugs are effective especially in patients with certain rare obesity forms. Hence, in the majority of patients, a pharmacological treatment could be an addendum to support and to stabilize the effect of a multimodal conservative treatment. The outlined strategic option should serve as a fundament for a discussion, which is essentially needed to turn the tide and establish a new and effective way to treat patients with obesity.

\section{Acknowledgments}

We are thankful to all our coworkers in the Institute of Experimental Pediatric Endocrinology, especially Dr. Sarah Paisdzior.

\section{Conflict of Interest Statement}

The authors have no conflicting interests to declare.

\section{Funding Sources}

This work was mainly supported by the Deutsche Forschungsgemeinschaft (DFG, German Research Foundation) through CRC 1423, project No. 421152132, subproject B02 (to P.K. and H.B.) for providing the experimental background of the manuscript, and KU 2673/6-1 (to P.K.).

\section{Author Contributions}

Peter Kühnen, Heike Biebermann, and Susanna Wiegand wrote the manuscript and approved it.

\section{References}

1 Studies OHP. The Heavy Burden of Obesity: The Economics of Prevention; 2019.

2 Geserick M, Vogel M, Gausche R, Lipek T, Spielau U, Keller E, et al. Acceleration of BMI in early childhood and risk of sustained obesity. N Engl J Med. 2018 Oct 4;379(14):1303-12.

3 Simmonds M, Burch J, Llewellyn A, Griffiths $\mathrm{C}$, Yang $\mathrm{H}$, Owen $\mathrm{C}$, et al. The use of measures of obesity in childhood for predicting obesity and the development of obesity-related diseases in adulthood: a systematic review and meta-analysis. Health Technol Assess. 2015 Jun;19(43):1-336.

4 Caprio S, Santoro N, Weiss R. Childhood obesity and the associated rise in cardiometabolic complications. Nat Metab. 2020 Mar;2(3): 223-32.

5 Pool LR, Aguayo L, Brzezinski M, Perak AM, Davis MM, Greenland P, et al. Childhood risk factors and adulthood cardiovascular disease: a systematic review. J Pediatr. 2021 May;232: 118-26.e23. 
6 Mygind L, Kurtzhals M, Nowell C, Melby PS, Stevenson MP, Nieuwenhuijsen M, et al. Landscapes of becoming social: a systematic review of evidence for associations and pathways between interactions with nature and socioemotional development in children. Environ Int. 2021 Jan;146:106238.

7 WHO. World Health Report. WHO; 2014.

8 WHO. Report: fiscal policies for diet and prevention of noncommunicable diseases. WHO; 2016.

9 Hall KD, Kahan S. Maintenance of lost weight and long-term management of obesity. Med Clin North Am. 2018 Jan;102(1):183-97.

10 Canuto R, Garcez A, de Souza RV, Kac G, Olinto MTA. Nutritional intervention strategies for the management of overweight and obesity in primary health care: a systematic review with meta-analysis. Obes Rev. 2021 Mar;22(3):e13143.

11 Inge $\mathrm{TH}$, Courcoulas $\mathrm{AP}$, Jenkins $\mathrm{TM}, \mathrm{Mi}$ chalsky MP, Brandt ML, Xanthakos SA, et al. Five-year outcomes of gastric bypass in adolescents as compared with adults. $\mathrm{N}$ Engl J Med. 2019 May 30;380(22):2136-45.

12 Son JW, Kim S. Comprehensive review of current and upcoming anti-obesity drugs. Diabetes Metab J. 2020 Dec;44(6):802-18.

13 Tak YJ, Lee SY. Long-term efficacy and safety of anti-obesity treatment: where do we stand? Curr Obes Rep. 2021 Mar;10(1):14-30.

14 Torgerson JS, Hauptman J, Boldrin MN, Sjöström L. XENical in the prevention of diabetes in obese subjects (XENDOS) study: a randomized study of orlistat as an adjunct to lifestyle changes for the prevention of type 2 diabetes in obese patients. Diabetes Care. 2004 Jan;27(1):155-61.

15 Gadde KM, Allison DB, Ryan DH, Peterson CA, Troupin B, Schwiers ML, et al. Effects of low-dose, controlled-release, phentermine plus topiramate combination on weight and associated comorbidities in overweight and obese adults (CONQUER): a randomised, placebo-controlled, phase 3 trial. Lancet. 2011 Apr 16;377(9774):1341-52.

16 Allison DB, Gadde KM, Garvey WT, Peterson CA, Schwiers ML, Najarian T, et al. Controlled-release phentermine/topiramate in severely obese adults: a randomized controlled trial (EQUIP). Obesity. 2012 Feb;20(2):33042.

17 Caixas A, Albert L, Capel I, Rigla M. Naltrexone sustained-release/bupropion sustainedrelease for the management of obesity: review of the data to date. Drug Des Devel Ther. 2014 Sep 18;8:1419-27.

18 Greig SL, Keating GM. Naltrexone ER/Bupropion ER: a review in obesity management. Drugs. 2015 Jul;75(11):1269-80.

19 Greenway FL, Fujioka K, Plodkowski RA, Mudaliar S, Guttadauria M, Erickson J, et al. Effect of naltrexone plus bupropion on weight loss in overweight and obese adults (COR-I) a multicentre, randomised, double-blind, placebo-controlled, phase 3 trial. Lancet. 2010 Aug 21;376(9741):595-605.
20 Apovian CM, Aronne L, Rubino D, Still C, Wyatt $\mathrm{H}$, Burns $\mathrm{C}$, et al. A randomized, phase 3 trial of naltrexone SR/bupropion SR on weight and obesity-related risk factors (CORII). Obesity. 2013 May;21(5):935-43.

21 Wadden TA, Foreyt JP, Foster GD, Hill JO, Klein S, O'Neil PM, et al. Weight loss with naltrexone SR/bupropion SR combination therapy as an adjunct to behavior modification: the COR-BMOD trial. Obesity. 2011 Jan; 19(1):110-20.

22 Hollander P, Gupta AK, Plodkowski R, Greenway F, Bays H, Burns C, et al. Effects of naltrexone sustained-release/bupropion sustained-release combination therapy on body weight and glycemic parameters in overweight and obese patients with type 2 diabetes. Diabetes Care. 2013 Dec;36(12):4022-9.

23 Secher A, Jelsing J, Baquero AF, HecksherSørensen J, Cowley MA, Dalbøge LS, et al. The arcuate nucleus mediates GLP-1 receptor agonist liraglutide-dependent weight loss. J Clin Invest. 2014 Oct;124(10):4473-88.

24 Ten Kulve JS, Veltman DJ, van Bloemendaal L, Barkhof F, Drent ML, Diamant M, et al. Liraglutide reduces CNS activation in response to visual food cues only after short-term treatment in patients with type 2 diabetes. Diabetes Care. 2016 Feb;39(2):214-21.

25 van Can J, Sloth B, Jensen CB, Flint A, Blaak EE, Saris WH. Effects of the once-daily GLP-1 analog liraglutide on gastric emptying, glycemic parameters, appetite and energy metabolism in obese, non-diabetic adults. Int J Obes. 2014 Jun;38(6):784-93

26 le Roux CW, Astrup A, Fujioka K, Greenway F, Lau DCW, Van Gaal L, et al. 3 years of liraglutide versus placebo for type 2 diabetes risk reduction and weight management in individuals with prediabetes: a randomised, double-blind trial. Lancet. 2017 Apr 8;389(10077): 1399-409.

27 Wadden TA, Hollander P, Klein S, Niswender $\mathrm{K}$, Woo V, Hale PM, et al. Weight maintenance and additional weight loss with liraglutide after low-calorie-diet-induced weight loss: the SCALE maintenance randomized study. Int J Obes. 2013 Nov;37(11):1443-51.

28 Davies MJ, Bergenstal R, Bode B, Kushner RF, Lewin A, Skjøth TV, et al. Efficacy of liraglutide for weight loss among patients with type 2 diabetes: the SCALE diabetes randomized clinical trial. JAMA. 2015 Aug 18;314(7):68799.

29 Pi-Sunyer X, Astrup A, Fujioka K, Greenway F, Halpern A, Krempf M, et al. A randomized, controlled trial of $3.0 \mathrm{mg}$ of liraglutide in weight management. N Engl J Med. 2015 Jul 2;373(1):11-22

30 Mead E, Brown T, Rees K, Azevedo LB, Whittaker V, Jones D, et al. Diet, physical activity and behavioural interventions for the treatment of overweight or obese children from the age of 6 to 11 years. Cochrane Database Syst Rev. 2017 Jun 22;6: CD012651.
31 Al-Khudairy L, Loveman E, Colquitt JL, Mead E, Johnson RE, Fraser H, et al. Diet, physical activity and behavioural interventions for the treatment of overweight or obese adolescents aged 12 to 17 years. Cochrane Database Syst Rev. 2017 Jun 22;6:CD012691.

32 Loveman E, Al-Khudairy L, Johnson RE, Robertson W, Colquitt JL, Mead EL, et al. Parent-only interventions for childhood overweight or obesity in children aged 5 to 11 years. Cochrane Database Syst Rev. 2015 Dec 21(12):CD012008

33 Schienkiewitz A, Damerow S, Schaffrath Rosario A. [Just method effects? Prevalences of underweight, overweight and obesity in children and adolescents according to the weighting factors and reference system used]. Bundesgesundheitsblatt Gesundheitsforschung Gesundheitsschutz. 2019 Oct;62(10): 1235-41.

34 Fornari E, Maffeis C. Treatment of metabolic syndrome in children. Front Endocrinol. 2019;10:702.

35 Katsagoni CN, Papachristou E, Sidossis A, Sidossis L. Effects of dietary and lifestyle interventions on liver, clinical and metabolic parameters in children and adolescents with non-alcoholic fatty liver disease: a systematic review. Nutrients. 2020 Sep 19; 12(9).

36 Tagi VM, Samvelyan S, Chiarelli F. Metabolic syndrome in children. Minerva Pediatr. 2020 Aug;72(4):312-25.

37 Farr OM, Pilitsi E, Mantzoros CS. Of mice and men: incretin actions in the central nervous system. Metabolism. 2019 Sep;98:12135.

38 Yeo GSH, Chao DHM, Siegert AM, Koerperich ZM, Ericson MD, Simonds SE, et al. The melanocortin pathway and energy homeostasis: from discovery to obesity therapy. $\mathrm{Mol}$ Metab. 2021 Mar 6;48:101206.

39 Boucsein A, Kamstra K, Tups A. Central signalling cross-talk between insulin and leptin in glucose and energy homeostasis. J Neuroendocrinol. 2021 Apr;33(4):e12944.

40 Tchang BG, Saunders KH, Igel LI. Best practices in the management of overweight and obesity. Med Clin North Am. 2021 Jan;105(1): 149-74.

41 Heymsfield SB, Wadden TA. Mechanisms, pathophysiology, and management of obesity. N Engl J Med. 2017 Jan 19;376(3):25466.

42 O'Connor EA, Evans CV, Burda BU, Walsh ES, Eder M, Lozano P. Screening for obesity and intervention for weight management in children and adolescents: evidence report and systematic review for the US Preventive Services Task Force. JAMA. 2017 Jun 20;317(23): 2427-44.

43 Ryder JR, Kaizer A, Rudser KD, Gross A, Kelly AS, Fox CK. Effect of phentermine on weight reduction in a pediatric weight management clinic. Int J Obes. 2017 Jan;41(1):903. 
44 Danne T, Biester T, Kapitzke K, Jacobsen SH, Jacobsen LV, Petri KCC, et al. Liraglutide in an adolescent population with obesity: a randomized, double-blind, placebo-controlled 5-week trial to assess safety, tolerability, and pharmacokinetics of liraglutide in adolescents aged 12-17 years. J Pediatr. 2017 Feb; 181:146-53.e3.

45 Kelly AS, Auerbach P, Barrientos-Perez M, Gies I, Hale PM, Marcus C, et al. A randomized, controlled trial of liraglutide for adolescents with obesity. N Engl J Med. 2020 May 28;382(22):2117-28.

46 Anker MS, Butler J, Anker SD. Liraglutide for adolescents with obesity. N Engl J Med. 2020 Sep 17;383(12):1192.

47 Page LC, Freemark M. Role of GLP-1 receptor agonists in pediatric obesity: benefits, risks, and approaches to patient selection. Curr Obes Rep. 2020 Dec;9(4):391-401.

48 Kelishadi R. Liraglutide for management of adolescent obesity. Nat Rev Endocrinol. 2020 Aug;16(8):405-6.

49 Weghuber D, Forslund A, Ahlström H, Alderborn A, Bergström K, Brunner S, et al. A 6-month randomized, double-blind, placebocontrolled trial of weekly exenatide in adolescents with obesity. Pediatr Obes. 2020 Jul; 15(7):e12624.

50 Yatvin MB, Dennis WH, Elegbede JA, Elson CE. Sensitivity of tumour cells to heat and ways of modifying the response. Symp Soc Exp Biol. 1987;41:235-67.

51 Czepiel KS, Perez NP, Campoverde Reyes KJ, Sabharwal S, Stanford FC. Pharmacotherapy for the treatment of overweight and obesity in children, adolescents, and young adults in a large health system in the US. Front Endocrinol. 2020;11:290.

52 Anderson K, Kelsberg G, Safranek S. Is metformin effective for reducing weight in obese or overweight adolescents? J Fam Pract. 2021 Mar;70(2):100-1.

53 Safer DL, Adler S, Dalai SS, Bentley JP, Toyama $\mathrm{H}$, Pajarito $\mathrm{S}$, et al. A randomized, placebo-controlled crossover trial of phenterminetopiramate ER in patients with binge-eating disorder and bulimia nervosa. Int J Eat Disord. $2020 \mathrm{Feb} ; 53(2): 266-77$.

54 Mead E, Atkinson G, Richter B, Metzendorf MI, Baur L, Finer N, et al. Drug interventions for the treatment of obesity in children and adolescents. Cochrane Database Syst Rev. 2016 Nov 29;11:CD012436.

55 Fox CK, Marlatt KL, Rudser KD, Kelly AS. Topiramate for weight reduction in adolescents with severe obesity. Clin Pediatr. 2015 Jan;54(1):19-24.

56 Calabrese F, Richetto J, Racagni G, Feldon J, Meyer U, Riva MA. Effects of withdrawal from repeated amphetamine exposure in peri-puberty on neuroplasticity-related genes in mice. Neuroscience. 2013 Oct 10;250:22231.

57 Kang S, Wu MM, Galvez R, Gulley JM. Timing of amphetamine exposure in relation to puberty onset determines its effects on anhe- donia, exploratory behavior, and dopamine D1 receptor expression in young adulthood. Neuroscience. 2016 Dec 17;339:72-84.

58 Denzer C, Denzer F, Lennerz BS, Vollbach H, Lustig RH, Wabitsch M. Treatment of hypothalamic obesity with dextroamphetamine: a case series. Obes Facts. 2019;12(1):91-102.

59 Horne VE, Bielamowicz K, Nguyen J, Hilsenbeck S, Lindsay H, Sonabend R, et al. Methylphenidate improves weight control in childhood brain tumor survivors with hypothalamic obesity. Pediatr Blood Cancer. 2020 Jul; 67(7):e28379

60 Poitou C, Mosbah H, Clément K. Mechanisms in endocrinology: update on treatments for patients with genetic obesity. Eur J Endocrinol. 2020 Nov;183(5):R149-66.

61 McCandless SE, Yanovski JA, Miller J, Fu C, Bird LM, Salehi P, et al. Effects of MetAP2 inhibition on hyperphagia and body weight in Prader-Willi syndrome: a randomized, double-blind, placebo-controlled trial. Diabetes Obes Metab. 2017 Dec;19(12):1751-61.

62 Salehi P, Hsu I, Azen CG, Mittelman SD, Geffner ME, Jeandron D. Effects of exenatide on weight and appetite in overweight adolescents and young adults with Prader-Willi syndrome. Pediatr Obes. 2017 Jun;12(3):221-8.

63 Motaghedi R, Lipman EG, Hogg JE, Christos PJ, Vogiatzi MG, Angulo MA. Psychiatric adverse effects of rimonobant in adults with Prader Willi syndrome. Eur J Med Genet. 2011 Jan-Feb;54(1):14-8.

64 Griggs JL, Sinnayah P, Mathai ML. PraderWilli syndrome: from genetics to behaviour, with special focus on appetite treatments. Neurosci Biobehav Rev. 2015 Dec;59:155-72.

65 Butler MG, Miller JL, Forster JL. Prader-Willi syndrome - clinical genetics, diagnosis and treatment approaches: an update. Curr Pediatr Rev. 2019;15(4):207-44.

66 Zhang Y, Proenca R, Maffei M, Barone M, Leopold L, Friedman JM. Positional cloning of the mouse obese gene and its human homologue. Nature. 1994 Dec 1;372(6505):42532.

67 Tartaglia LA, Dembski M, Weng X, Deng N, Culpepper J, Devos R, et al. Identification and expression cloning of a leptin receptor, OB-R. Cell. 1995 Dec 29;83(7):1263-71.

68 Chen H, Charlat O, Tartaglia LA, Woolf EA, Weng X, Ellis SJ, et al. Evidence that the diabetes gene encodes the leptin receptor: identification of a mutation in the leptin receptor gene in $\mathrm{db} / \mathrm{db}$ mice. Cell. 1996 Feb 9;84(3): 491-5.

69 Jackson RS, Creemers JW, Ohagi S, RaffinSanson ML, Sanders L, Montague CT, et al. Obesity and impaired prohormone processing associated with mutations in the human prohormone convertase 1 gene. Nat Genet. $1997 \mathrm{Jul} ; 16(3): 303-6$

70 Montague CT, Farooqi IS, Whitehead JP, Soos MA, Rau H, Wareham NJ, et al. Congenital leptin deficiency is associated with severe early-onset obesity in humans. Nature. 1997 Jun 26;387(6636):903-8.
71 Clement K, Vaisse C, Lahlou N, Cabrol S, Pelloux V, Cassuto D, et al. A mutation in the human leptin receptor gene causes obesity and pituitary dysfunction. Nature. $1998 \mathrm{Mar}$ 26;392(6674):398-401.

72 Krude H, Biebermann H, Luck W, Horn R, Brabant G, Grüters A. Severe early-onset obesity, adrenal insufficiency and red hair pigmentation caused by POMC mutations in humans. Nat Genet. 1998 Jun;19(2):155-7.

73 Vaisse C, Clement K, Guy-Grand B, Froguel P. A frameshift mutation in human MC4R is associated with a dominant form of obesity. Nat Genet. 1998 Oct;20(2):113-4.

74 Yeo GS, Farooqi IS, Aminian S, Halsall DJ, Stanhope RG, O'Rahilly S. A frameshift mutation in MC4R associated with dominantly inherited human obesity. Nat Genet. 1998 Oct; 20(2):111-2.

75 Farooqi IS, Jebb SA, Langmack G, Lawrence E, Cheetham CH, Prentice AM, et al. Effects of recombinant leptin therapy in a child with congenital leptin deficiency. N Engl J Med. 1999 Sep 16;341(12):879-84.

76 DePaoli AM. 20 years of leptin: leptin in common obesity and associated disorders of metabolism. J Endocrinol. 2014 Oct;223(1):T7181.

77 Heymsfield SB, Greenberg AS, Fujioka K, Dixon RM, Kushner R, Hunt T, et al. Recombinant leptin for weight loss in obese and lean adults: a randomized, controlled, dose-escalation trial. JAMA. 1999 Oct 27;282(16):156875.

78 Greenfield JR, Miller JW, Keogh JM, Henning E, Satterwhite JH, Cameron GS, et al. Modulation of blood pressure by central melanocortinergic pathways. N Engl J Med. 2009 Jan 1; 360(1):44-52.

79 Krishna R, Gumbiner B, Stevens C, Musser B Mallick M, Suryawanshi S, et al. Potent and selective agonism of the melanocortin receptor 4 with MK-0493 does not induce weight loss in obese human subjects: energy intake predicts lack of weight loss efficacy. Clin Pharmacol Ther. 2009 Dec;86(6):659-66.

80 Haws R, Brady S, Davis E, Fletty K, Yuan G, Gordon G, et al. Effect of setmelanotide, a melanocortin-4 receptor agonist, on obesity in Bardet-Biedl syndrome. Diabetes Obes Metab. 2020 Nov;22(11):2133-40.

81 Iepsen EW, Zhang J, Thomsen HS, Hansen EL, Hollensted M, Madsbad S, et al. Patients with obesity caused by melanocortin- 4 receptor mutations can be treated with a glucagon-like peptide-1 receptor agonist. Cell Metab. 2018 Jul 3; 28(1):23-32.e3.

82 Iepsen EW, Have CT, Veedfald S, Madsbad S, Holst JJ, Grarup N, et al. GLP-1 receptor agonist treatment in morbid obesity and type 2 diabetes due to pathogenic homozygous melanocortin-4 receptor mutation: a case report. Cell Rep Med. 2020 Apr 21;1(1):100006.

83 Sriram K, Insel PA. G protein-coupled receptors as targets for approved drugs: how many targets and how many drugs? Mol Pharmacol. 2018 Apr;93(4):251-8. 
84 Santos R, Ursu O, Gaulton A, Bento AP, Donadi RS, Bologa CG, et al. A comprehensive map of molecular drug targets. Nat Rev Drug Discov. 2017 Jan;16(1):19-34.

85 Lefkowitz RJ. Seven transmembrane receptors: something old, something new. Acta Physiol. 2007 May;190(1):9-19.

86 Alexander SP, Christopoulos A, Davenport AP, Kelly E, Marrion NV, Peters JA, et al. The concise guide to pharmacology 2017/18: G proteincoupled receptors. Br J Pharmacol. 2017 Dec 174(Suppl 1):S17-S129.

87 Biebermann H, Kühnen P, Kleinau G, Krude H. The neuroendocrine circuitry controlled by POMC, MSH, and AGRP. Handb Exp Pharmacol. 2012(209):47-75.

88 Inoue A, Raimondi F, Kadji FMN, Singh G, Kishi $\mathrm{T}$, Uwamizu A, et al. Illuminating G-protein-coupling selectivity of GPCRs. Cell. 2019 Jun 13;177(7): 1933-47.e25

89 Marti-Solano M, Crilly SE, Malinverni D, Munk C, Harris M, Pearce A, et al. Combinatorial expression of GPCR isoforms affects signalling and drug responses. Nature. 2020 Nov; 587(7835):650-6

90 Vassilatis DK, Hohmann JG, Zeng H, Li F, Ranchalis JE, Mortrud MT, et al. The G proteincoupled receptor repertoires of human and mouse. Proc Natl Acad Sci U S A. 2003 Apr 15; 100(8):4903-8.

91 Ritter SL, Hall RA. Fine-tuning of GPCR activity by receptor-interacting proteins. Nat Rev Mol Cell Biol. 2009 Dec;10(12):819-30.

92 Kleinau G, Müller A, Biebermann H. Oligomerization of GPCRs involved in endocrine regulation. J Mol Endocrinol. 2016 Jul;57(1): R59-80.

93 Nikolaev VO, Moshkov A, Lyon AR, Miragoli M, Novak P, Paur H, et al. Beta2-adrenergic receptor redistribution in heart failure changes cAMP compartmentation. Science. 2010 Mar 26;327(5973):1653-7.

94 Bock A, Annibale P, Konrad C, Hannawacker A, Anton SE, Maiellaro I, et al. Optical mapping of cAMP signaling at the nanometer scale. Cell. 2020 Sep 17;182(6):1519-30.e17.

95 Barnes PJ. Receptor heterodimerization: a new level of cross-talk. J Clin Invest. 2006 May; 116(5):1210-2.

96 McGraw DW, Mihlbachler KA, Schwarb MR, Rahman FF, Small KM, Almoosa KF, et al. Airway smooth muscle prostaglandin-EP1 receptors directly modulate beta2-adrenergic receptors within a unique heterodimeric complex. J Clin Invest. 2006 May;116(5):1400-9.

97 Van der Ploeg LH, Martin WJ, Howard AD, Nargund RP, Austin CP, Guan X, et al. A role for the melanocortin 4 receptor in sexual function. Proc Natl Acad Sci U S A. 2002 Aug 20; 99(17):11381-6

98 Kuhnen P, Krude H, Biebermann H. Melanocortin-4 receptor signalling: importance for weight regulation and obesity treatment. Trends Mol Med. 2019 Feb;25(2):136-48.
99 Adank DN, Lunzer MM, Ericson MD, Koeperich ZM, Wilber SL, Fleming KA, et al. Comparative intracerebroventricular and intrathecal administration of a nanomolar macrocyclicmelanocortin receptoragonistMDE6-5-2c (c[Pro-His-DPhe-Arg-Trp-Dap-Ala-DPro]) decreases food intake in mice. ACS Chem Neurosci. 2020 Oct 7;11(19):3051-63.

100 Rediger A, Tarnow P, Bickenbach A, Schaefer M, Krude H, Gruters A, et al. Heterodimerization of hypothalamic G-protein-coupled receptors involved in weight regulation. Obes Facts. 2009;2(2):80-6.

101 Foster SR, Hauser AS, Vedel L, Strachan RT, Huang XP, Gavin AC, et al. Discovery of human signaling systems: pairing peptides to $G$ protein-coupled receptors. Cell. 2019 Oct 31; 179(4):895-908.e21.

102 Quinones M, Ferno J, Dieguez C, Nogueiras $\mathrm{R}$, Al-Massadi O. Exciting advances in GPCRbased drugs discovery for treating metabolic disease and future perspectives. Expert Opin Drug Discov. 2019 May;14(5):421-31.

103 Mohr K, Schmitz J, Schrage R, Tränkle C, Holzgrabe U. Molecular alliance-from orthosteric and allosteric ligands to dualsteric/bitopic agonists at $\mathrm{G}$ protein coupled receptors. Angew Chem Int Ed Engl. 2013 Jan 7;52(2):508-16.

104 Nickols HH, Conn PJ. Development of allosteric modulators of GPCRs for treatment of CNS disorders. Neurobiol Dis. 2014 Jan;61: $55-71$.

105 Murphy T, Le Foll B. Targeting the endocannabinoid CB1 receptor to treat body weight disorders: a preclinical and clinical review of the therapeutic potential of past and present CB1 drugs. Biomolecules. 2020 Jun 4;10(6).

106 Sharma S, Garfield AS, Shah B, Kleyn P, Ichetovkin I, Moeller IH, et al. Current mechanistic and pharmacodynamic understanding of melanocortin-4 receptor activation. Molecules. 2019 May 16;24(10).

107 Kuhnen P, Clement K, Wiegand S, Blankenstein $\mathrm{O}$, Gottesdiener K, Martini LL, et al. Proopiomelanocortin deficiency treated with a melanocortin-4 receptor agonist. N Engl J Med. 2016 Jul 21;375(3):240-6.

108 Clement K, Biebermann H, Farooqi IS, Van der Ploeg L, Wolters B, Poitou C, et al. MC4R agonism promotes durable weight loss in patients with leptin receptor deficiency. Nat Med. 2018 May;24(5):551-5.

109 Gamage TF, Lichtman AH. The endocannabinoid system: role in energy regulation. Pediatr Blood Cancer. 2012 Jan;58(1):144-8

110 Moreira FA, Crippa JA. The psychiatric sideeffects of rimonabant. Braz J Psychiatry. 2009 Jun;31(2):145-53.

111 Poggioli R, Vergoni AV, Bertolini A. ACTH(1-24) and alpha-MSH antagonize feeding behavior stimulated by kappa opiate agonists. Peptides. 1986 Sep-Oct;7(5):843-8.

112 Hruby VJ, Sharma SD, Toth K, Jaw JY, alObeidi F, Sawyer TK, et al. Design, synthesis, and conformation of superpotent and prolonged acting melanotropins. Ann N Y Acad Sci. 1993 May 31;680:51-63.
113 Goncalves JPL, Palmer D, Meldal M. MC4R agonists: structural overview on antiobesity therapeutics. Trends Pharmacol Sci. 2018 Apr;39(4):402-23

114 Yang LK, Tao YX. Biased signaling at neural melanocortin receptors in regulation of energy homeostasis. Biochim Biophys Acta Mol Basis Dis. 2017 Oct;1863(10 Pt A):2486-95.

115 Li YQ, Shrestha Y, Pandey M, Chen M, Kablan A, Gavrilova O, et al. G(q/11) $\alpha$ and $\mathrm{G}(\mathrm{s}) \alpha$ mediate distinct physiological responses to central melanocortins. J Clin Invest. 2016 Jan; 126(1):40-9.

116 Chiappini F, Cunha LL, Harris JC, Hollenberg AN. Lack of cAMP-response element-binding protein 1 in the hypothalamus causes obesity. J Biol Chem. 2011 Mar 11;286(10):8094-105.

117 Sloop KW, Emmerson PJ, Statnick MA, Willard FS. The current state of GPCR-based drug discovery to treat metabolic disease. Br J Pharmacol. 2018 Nov;175(21):4060-71.

118 Drucker DJ, Nauck MA. The incretin system: glucagon-like peptide-1 receptor agonists and dipeptidyl peptidase- 4 inhibitors in type 2 diabetes. Lancet. 2006 Nov 11;368(9548):1696705 .

119 Muller TD, Finan B, Clemmensen C, DiMarchi RD, Tschop MH. The new biology and pharmacology of glucagon. Physiol Rev. 2017 Apr;97(2):721-66.

120 Muller TD, Finan B, Bloom SR, D’Alessio D, Drucker DJ, Flatt PR, et al. Glucagon-like peptide 1 (GLP-1). Mol Metab. 2019 Dec;30:72130.

121 Novikoff A, O’Brien SL, Bernecker M, Grandl G, Kleinert M, Knerr PJ, et al. Spatiotemporal GLP-1 and GIP receptor signaling and trafficking/recycling dynamics induced by selected receptor mono- and dual-agonists. Mol Metab. 2021 Feb 6;49:101181.

122 Finan B, Yang B, Ottaway N, Stemmer K, Müller TD, Yi CX, et al. Targeted estrogen delivery reverses the metabolic syndrome. Nat Med. 2012 Dec;18(12):1847-56.

123 Finan B, Clemmensen C, Zhu Z, Stemmer K, Gauthier K, Müller L, et al. Chemical hybridization of glucagon and thyroid hormone optimizes therapeutic impact for metabolic disease. Cell. 2016 Oct 20;167(3):843-57.e14.

124 Jepsen MM, Christensen MB. Emerging glucagon-like peptide 1 receptor agonists for the treatment of obesity. Expert Opin Emerg Drugs. 2021 Jul 6; 1-13. doi: 10.1080/14728214. 2021.1947240.

125 Wilding JPH, Batterham RL, Calanna S, Davies $\mathrm{M}$, Van Gaal LF, Lingvay I, McGowan BM, Rosenstock J, Tran MTD, Wadden TA, Wharton S, Yokote K, Zeuthen N, Kushner RF, STEP 1 Study Group. Once-Weekly Semaglutide in Adults with Overweight or Obesity. N Engl J Med. 2021 Mar 18;384(11):989. doi: 10.1056/NEJMoa2032183.

126 Tamborlane WV, Fainberg U, Barrett T. Liraglutide in Children and Teens with Type 2 Diabetes. Reply. N Engl J Med. 2019 Oct 31;381(18):1787. doi: 10.1056/ NEJMc1912498. 